\title{
KAJIAN CITRA RESOLUSI TINGGI WORLDVIEW-2 SEBAGAI PENUNJANG DATA DASAR UNTUK RENCANA DETAIL TATA RUANG KOTA (RDTRK) (Studi Kasus: Kecamatan Rungkut, Surabaya)
}

\author{
Heri Setiawan, Yanto Budisusanto \\ Program Studi Teknik Geomatika, FTSP, ITS-Sukolilo, Surabaya, 60111 \\ Email : herjrutoz@gmail.com
}

\begin{abstract}
Abstrak
Suatu kawasan perkotaan merupakan kawasan dengan jumlah penduduk lebih banyak dibandingan dengan daerah pinggiran maupun plosok. Salah satunya adalah Kotas Surabaya yang memiliki unit-unit pengembangan. Salah satu unit pengembangann dari Kota Surabaya adalah Kecamatan Rungkut. Kecamatan Rungktu, kecamatan rungkut memiliki kawasan industri yang luas dibandingkan lainnya sehingga mengakibatkan banyaknya pertambahan penduduk di kota besar,adanya ketidak seimbangan itu perlu memeperhatikan suatu penataan rung yang baik. Penataan ruang yang baik yaitu mempertimbangkan keselarasan antara kegiatan utama dengan kawasan fungsional. Penataan ruang yang baik di wujudkan dalam Rencana Detail Tata Ruang Kota (RDTRK). RDTRK merupakan kawasan dengan blok pemanfaatan ruang, terkait dengan penyusunan RDTRK dibutuhkan suatu data dasar. Data dasar yang dimaksud dapat berupa Citra resolusi tinggi ataupun foto udara.
\end{abstract}

Data dasar yang dimaksud dapat diperoleh dengan berbagai cara, salah satu untuk mendapatkan data dasar yang layak yaitu menggunakan teknologi penginderaan jauh. Pada penelitian ini dilakukan pengolahan citra menggunakan klasifikasi dijital dan interpretasi manual. Klasifikasi dijital menggunakan jenis maximum likelihood sedangkan interpretasi manual menggunakan 7 kunci interpretasi.

Hasil yang diperoleh dari penelitian ini adalah koreksi geometrik sebesar 0,29. Penelitian ini akan mengkaji kelayakan citra yang digunakan untuk penunjang data dasar dari RDTRK. Hasi Dari uji ketelitian klasifikassi citra worldvie-2 sebesar $89,7 \%$ dengan jumlah kelas tutupan lahan sebanyak 7 kelas yaitu semak belukar, lahan kosong, sungai, pemukiman, jalan, tambak dan industri. Yang kemudian di kaji kesesuaianya dengan RDTRK.

Kata Kunci : RDTRK, Worldview-2, Kecamatan Rungkut

\section{PENDAHULUAN \\ Latar Belakang}

Wilayah Surabaya Timur adalah kawasan dengan blok pendidikan, kawasan lindung dan industri. Salah satu kecamatan yang ada di wilayah Surabaya Timur yaitu Kecamatan Rungkut. Kecamatan Rungkut merupakan kecamatan dengan luas area sebesar 21,02 $\mathrm{km}^{2}$.

Dalam RDTRK dibutuhkan data dasar yang sesuai untuk menunjang penyusunanya. Data dasar itu sendiri adalah data awal yang digunakan sebagai acuan dalam melakukan penyusunan RDTRK, data dasar yang dimaksud meliputi prasarana dan utilitas umum, kependudukan, perekonomian, penggunaan lahan, tata bangunan dan lingkungan, daerah rawan bencana serta fisik dasar kawasan. Salah satu cara untuk mendapatkan data dasar tersebut dengan menggunakan teknologi penginderaan jauh. Terkait dengan data dasar RDTRK yang memberikan informasi tentang muka bumi dapat berupa citra satelit maupun foto udara dengan teknologi tersebut. Jika menggunakan metode pemetaan konvensional akan sangat rumit dan memerlukan waktu yang lama serta biaya yang sangat tinggi.

Oleh karena itu salah satu solusi untuk mendapatkan data yang berkualitas dengan menggunakan aplikasi teknologi penginderaan jauh yaitu dengan citra satelit resolusi tinggi salah satunya worldview2. WorldView2 merupakan salah satu satelit yang diluncurkan oleh Digital Globe tahun 2009 dengan resolusi spasial 1,84 m (multispektral) dan 0,5 m (pankromatrik). Satelit ini digunakan untuk mendukung perencanaan 
infrastruktur, perencanaan kota, dan penaksiran dampak visual. Penggunaan satelit ini diharapkan dapat memberikan gambaran secara lebih detail terhadap interpretasi permukaan bumi yang bisa dilakukan pembaharuan data, dan sebagai data penunjang untuk detail tata ruang secara cepat, efisien dan murah

\section{Perumusan Masalah}

Perumusan masalah yang dimunculkan dalam penelitian ini adalah sebagai berikut :

1. Bagaimanakah kelayakan Citra yang digunakan untuk data dasar dalam penentuan Rencana Detail Tata Ruang Kota di Kecamatan Rungkut Surabaya?

2. Bagaimanakah kesesuaian lahan dari kajian Citra Worldview-2 terhadap RDTRK?

\section{METODOLOGI PENELITIAN}

\section{Lokasi Penelitian}

Lokasi penelitian Tugas Akhir ini mengambil daerah studi di Kecamatan Rungkut. Secara geografis terletak pada koordinat $07^{\circ} 43^{\prime} \mathrm{LS}$ sampai $08^{\circ} 46^{\prime}$ LS dan $113^{\circ} 53^{\prime}$ BT sampai $114^{\circ}$ 38' BT dengan batas sebelah utara : Kecamatan Sukolilo, batas sebelah timur: Selat Madura, batas sebelah selatan: Kecamatan Gunung Anyar, sebelah barat: Kecamatan Tenggilis Mejoyo adapun luas Kecamatan Rungkut $21,02 \mathrm{~km}^{2}$.

\section{Data dan Peralatan \\ Data}

Data yang dibutuhkan dalam penelitian Tugas Akhir ini antara lain :

a. Citra Worldview-2 Kota Surabaya 2012.

b. Peta Garis Kota Surabaya1:5000 dari foto udara tahun 2002.

c. Peta RDTRK Surabaya skala $1: 5000$.

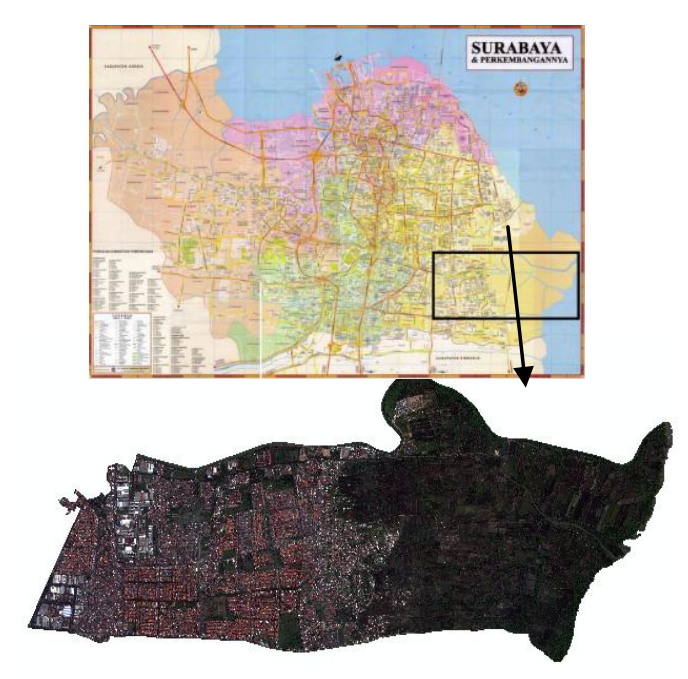

Gambar 1. Lokasi Penelitian

\section{Peralatan}

Peralatan yang digunakan dalam penelitian ini adalah Personal Computer (PC) / Notebook, Microsoft Office Excel, software pengolahan citra digital, ArcGIS 9.3, GPS Handheld.

\section{Tahapan Penelitian}

Diagram Alir proses Pengolahan Data pada penelitian ini ditunjukkan oleh Gambar 2.

Berikut adalah penjelasan diagram alir tahapan pengolahan data :

a. Mosaik

Proses ini bertujuan untuk menggabungkan citra agar dapat mencangkup area studi yang digunakan untuk penelitian Tugas Akhir ini.

b. Koreksi Geometrik

Proses Koreksi geometrik pada Citra dilakukan dengan menggunakan Software ER Mapper 7.0. dengan persebaran 7 titik GCP. Dengan menghasilkan nilai RMS Error. Rektifikasi dilakukan untuk memperbaiki kondisi piksel citra akibat dilakukan registrasi (piksel citra tertarik karena memposisikan citra sesuai acuan yang digunakan berdasarkan GCP).

Setelah proses Koreksi Geometik memenuhi syarat nilai RMS Error 1 pixel, kemudian dilakukan Verifikasi Koreksi Geometrik dengan cara menampalkan (overlay) citra dengan peta acuan yaitu Peta Garis Surabaya tahun 2002. 


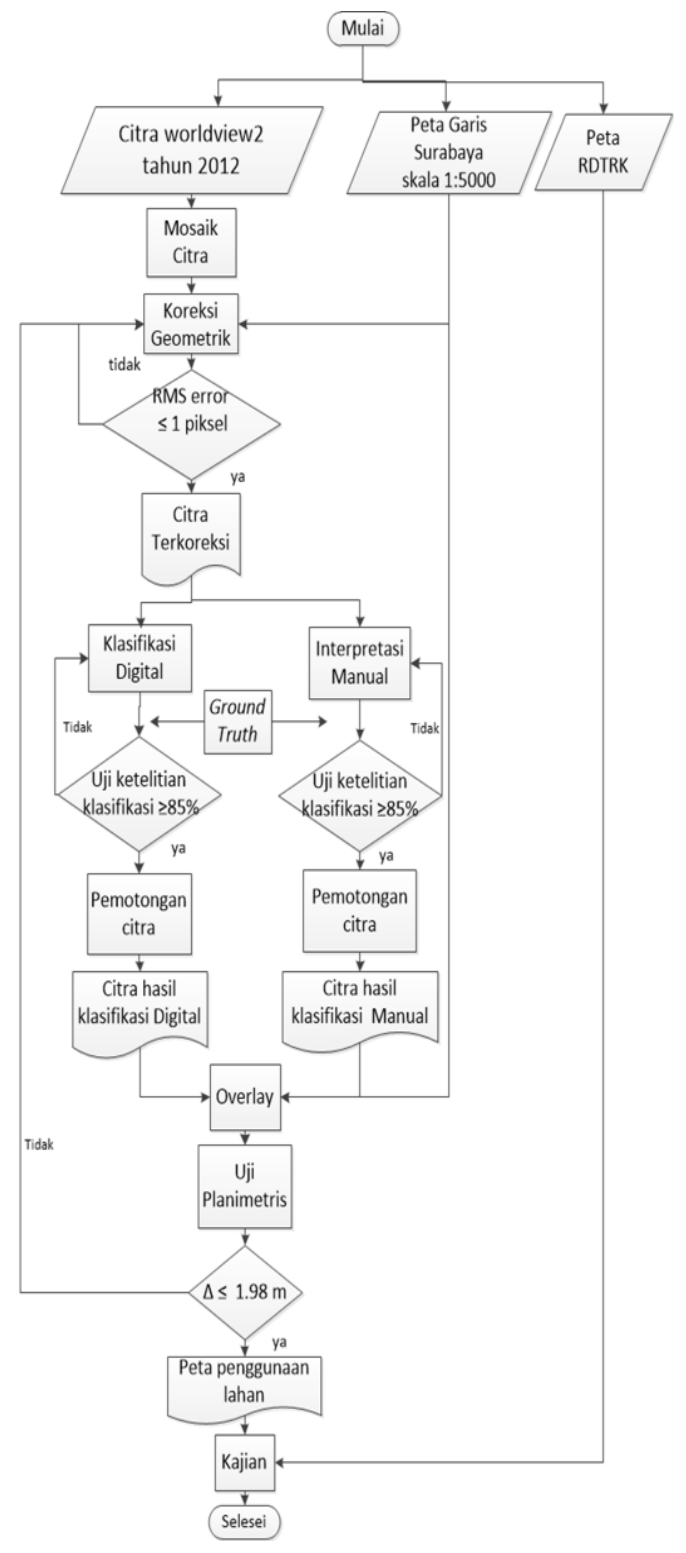

Gambar 2. Diagram Alir Tahapan Pengolahan Data

c. Klasifikasi

Pada tahapan ini dilakukan pengklasifikasian yaitu klasifikasi dijital dengan menggunakan software untuk sampling objek dan manual menggunakan kunci interpretasi.

d. Pemotongan Citra

Proses ini dilakukan untuk memperoleh citra yang hanya mencakup area penelitian, supaya proses pengolahannya menjadi lebih efektif dan memperkecil memori penyimpanan.

e. Interpretasi Citra

Interpretasi citra merupakan kegiatan mengkaji foto udara atau citra dengan maksud untuk mengidentifikasi obyek yang tergambar dalam citra dan menilai arti penting obyek tersebut.

f. Overlay citra worldview2 dan Peta Garis Surabaya skala 1:5000. Hasil pemotongan Citra 2012 tersebut kemudian diklasifikasikan selanjutnya dioverlaykan dengan Peta Garis 1:5000 untuk dilakukan perhitungan dari pergeseran linearnya.

g. Uji Planimetris

Bertujuan untuk mengetahui pergeseran yang terjadi dari hasil overlay citra dengan peta garis skala 1:5000 dengan minimal pergeseranya adalah $1.68 \mathrm{~m}$.

h. Peta Penggunaan Lahan

Hasil dari proses uji ketelitian planimetris berupa peta penggunaan lahan yang nantinya akan dilakukan pengkajian menggunakan peta RDTRK.

i. Kajian

Kajian ini bertujuan unutk melakukan anlisa terhadap hasil peta tutupan lahan dengan peta RDTRK untuk mengetahui kesesuaianya.

\section{HASIL DAN ANALISA}

Hasil

1. Hasil dari proses pengolahan dan perhitungan adalah sebagai berikut :

a. Koreksi Geometrik Hasil Koreksi Geometrik dengan syarat nilai RMS Error 1 pixel, Citra Worldview-2 diperoleh 7 GCP dengan rata - rata $R M S$ Error 0,29 yang diterapkan.

b. Klasifikasi dijital

Hasil klasifikasi menghasilkan 7 kelas tutupan lahan yang akan dikaji dimana hasilnya dapat dilihat pada gambar di bawah ini : 


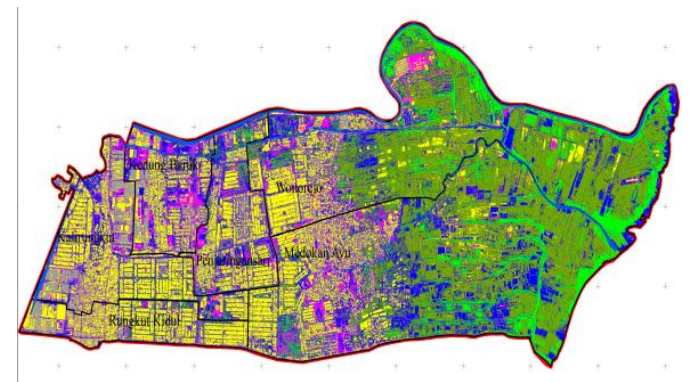

Gambar 3. Hasil Klasifikasi Dijital

Terdapat 7 kelas tutupan lahan dengan nilai uji klasifikasi 87,9\%. Nilai tersebut didapatkan dari confusion matrix pada software

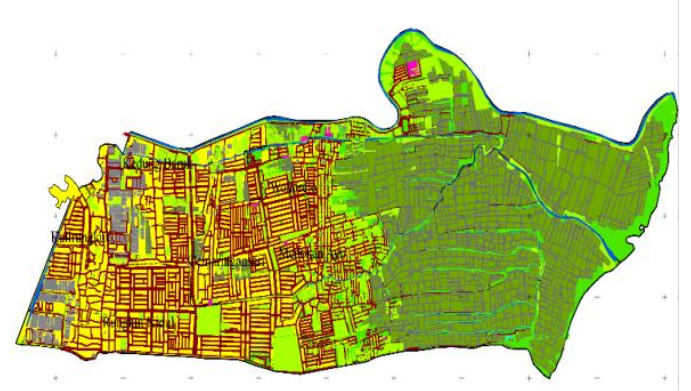

Gambar 4. Hasil Interpretasi Manual

\section{Unsur obyek pada klasifikasi}

a. Kelas Tambak

\begin{tabular}{|l|l|}
\hline $\begin{array}{l}\text { Hasil Klasifikasi } \\
\text { Digital }\end{array}$ & $\begin{array}{l}\text { Hasil Interpretasi } \\
\text { Manual }\end{array}$ \\
\hline & \\
\hline
\end{tabular}

Gambar 5. Tambak

Dari hasil klasifikasi tutupan lahan kelas Tamabak seperti tabel di atas menandakan bahwa hasil dari klasifikasi dijital menunjukkan kebenaran yang akurat saat hasil tersebut dibandingkan dengan data hasil interpretasi manual, yaitu dibuktikan dengan tidak adanya piksel-piksel kelaas lain yang masuk kedalam hasil klasifikasi kelas tambak tersebut. Area kelas tambak ini ditandai dengan batas garis poligon berwarna merah pada hasil klasifikasi dijital dan interpretaasi manual.

\section{b. Kelas Pemukiman}

Dari hasil klasifikasi tutupan lahan kelas pemukiman di atas menandakan bahwa hasil klasifikasi dijital menunjukkan kebenaran yang akurat saat hasil tersebut dibandingkan dengan data hasil interpretasi manual yaitu hampir tidak ada piksel-piksel kelas lain yang masuk ke dalam klasifikasi kelas pemukiman di atas.

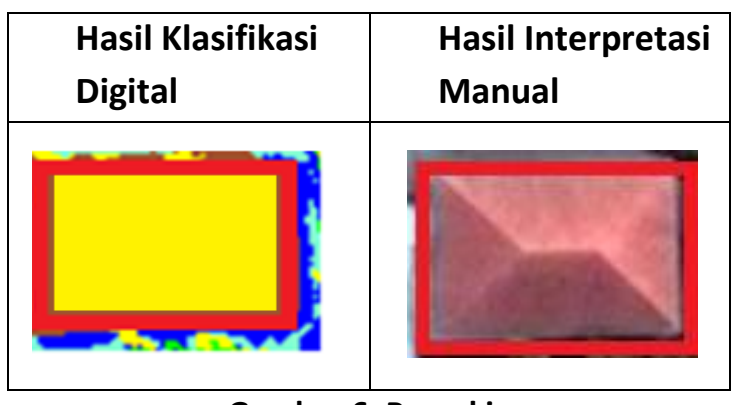

Gambar 6. Pemukiman

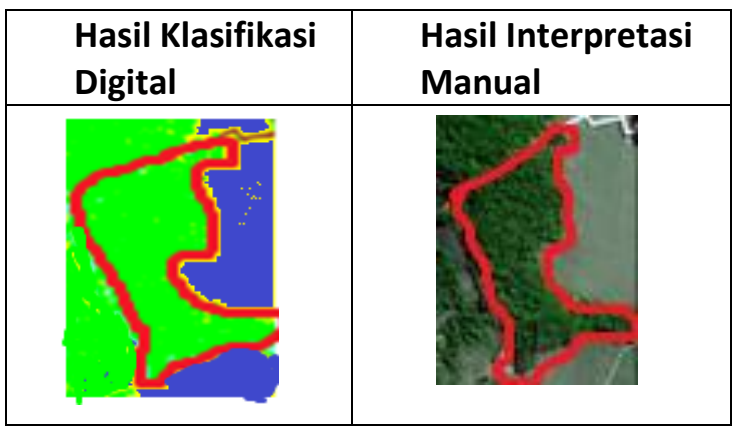

Gambar 7. Semak Belukar
Dari hasil klasifikasi tutupan lahan kelas semak belukar seperti tabel di aatas menandakan bahwa hasil dari klasifikasi dijital menunjukkan kebenaran yang akurat saat hasil tersebut dibandingkan dengan data hasil interpretasi manual, yaitu dibuktikan dengan tidak adanya pikselpiksel kelas lain yang masuk kedalam hasil klasifikasi kelas semak belukar tersebut. Interpretasi maual juga akurat diamati dengan objek yang ada pada citra itu sendiri. 


\section{d. Kelas Lahan Kosong}

Dari hasil klasifikasi tutupan lahan kelas lahan kosong seperti tabel $\mathrm{di}$ atas menandakan bahwa hasil dari klasifikasi dijital menunjukkan kebenaran yang akurat saat hasil tersebut dibandingkan dengan data hasil interpretasi manual, yaitu dibuktikan dengan tidak adanya pikselpiksel kelaas lain yang masuk kedalam hasil klasifikasi kelas lahan kosong tersebut.

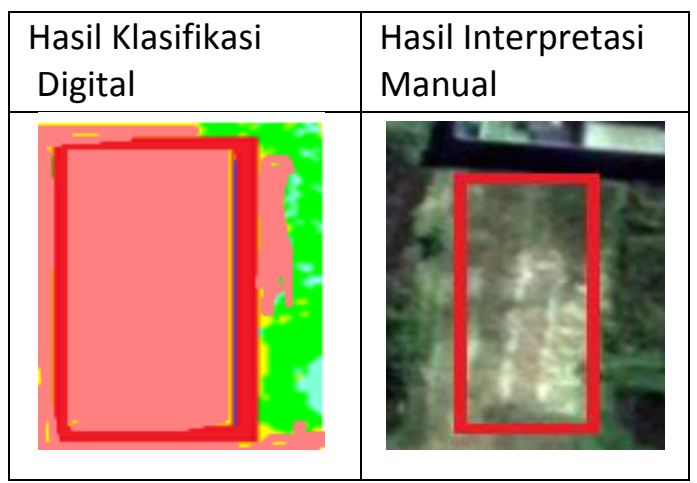

Gambar 8. Lahan Kosong

\section{e. Kelas Industri}

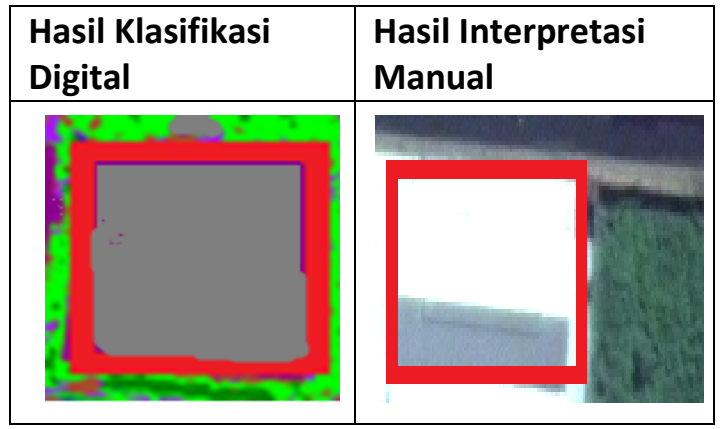

Gambar 9. Industri

Dari hasil klasifikasi tutupan lahan kelas industri seperti gamabar di atas menandakan bahwa hasil dari klasifikasi dijital menunjukkan kebenaran yang akurat saat hasil tersebut dibandingkan dengan data hasil interpretasi manual, yaitu dibuktikan dengan tidak adanya piksel-piksel kelaas lain yang masuk kedalam hasil klasifikasi kelas industri tersebut.

\section{f. Kelas Sungai}

Dari hasil klasifikasi tutupan lahan kelas sungai seperti gambar di atas menandakan bahwa hasil dari klasifikasi dijital menunjukkan kebenaran yang akurat dan manual. Sedangkan untuk yang manual menunjukan kenampakan yang sesuai dengan klasifikasi dijital.

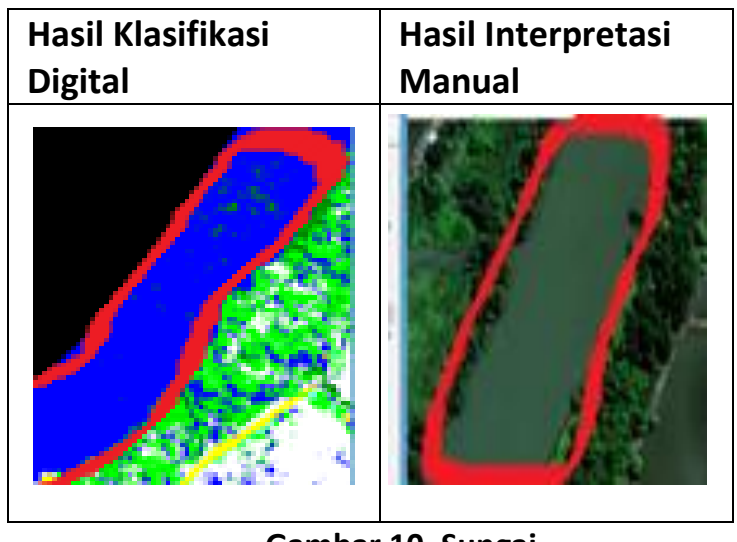

Gambar 10. Sungai

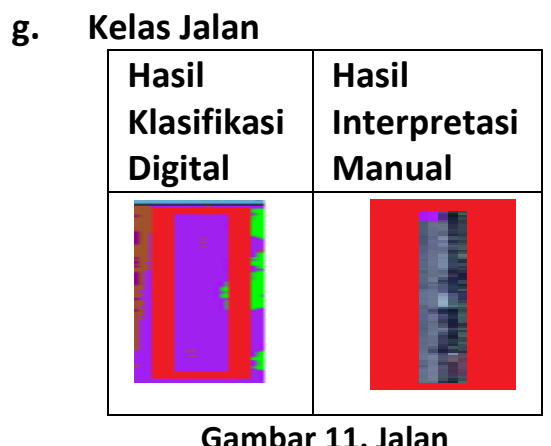

Dari hasil klasifikasi tutupan lahan kelas jalan seperti gambar di atas menandakan bahwa hasil dari klasifikasi dijital menunjukkan kebenaran yang akurat saat hasil tersebut dibandingkan dengan data hasil interpretasi manual, yaitu dibuktikan dengan tidak adanya piksel-piksel kelaas lain yang masuk kedalam hasil klasifikasi kelas jalan tersebut.

\section{Analisa Ketelitian Skala Peta berdasarkan \\ Standar Kartografi}

Dari sebaran 36 titik sampel pada masingmasing area penelitian yang terdapat pada lampiran dapat diketahui bahwa antara hasil pengolahan citra dengan menggunakan metode klasifikasi dijital dan klasifikasi manual mengalami pergeseran linier/penyimpangan jarak pada masingmasing batas kelas tutupan lahan yang dijadikan sebagai titik sampel. 
Penyimpangan koordinat terbesar dari 36 titik sampel koordinat $X$ pada Kecamatan Rungkut, Surabaya Timur sebesar $2.48 \mathrm{~m}$ dan besar penyimpangan terkecilnya sebesar $0 \mathrm{~m}$ (tidak adanya penyimpangan koordinat), begitu juga dengan besar penyimpangan koordinat yang terdapat pada titik sampel koordinat $Y$ pada kecamatan Rungkut, Surabaya Timur sebesar $2.99 \mathrm{~m}$ dan besar persimpangan terkecilnya sebesar $0 \mathrm{~m}$ (tidak adanya penyimpangan jarak).

Tabel 1 Penyimpangan Rata-rata Koordinat

\begin{tabular}{|c|c|c|}
\hline $\begin{array}{c}\text { Area } \\
\text { Penelitian }\end{array}$ & $\begin{array}{c}\text { Koordinat } \\
\mathbf{X}(\mathbf{m})\end{array}$ & $\begin{array}{c}\text { Koordinat } \\
\mathbf{Y}(\mathbf{m})\end{array}$ \\
\hline $\begin{array}{c}\text { Kecamatan } \\
\text { Rungkut }\end{array}$ & 0.8 & 0.6 \\
\hline
\end{tabular}

Tabel 2 Penyimpangan Jarak

\begin{tabular}{|l|l|l|l|}
\hline $\begin{array}{c}\text { Area } \\
\text { Penelitian }\end{array}$ & $\begin{array}{l}\text { Terbesar } \\
(\mathrm{m})\end{array}$ & $\begin{array}{l}\text { Terkecil } \\
(\mathrm{m})\end{array}$ & $\begin{array}{l}\text { Rata- } \\
\text { rata } \\
(\mathrm{m})\end{array}$ \\
\hline $\begin{array}{l}\text { Kecamatan } \\
\text { Rungkut }\end{array}$ & 2.99 & 0 & 1.06 \\
\hline
\end{tabular}

\section{Kajian Kesesuaian Citra Worldview-2 dengan RDTRK}

Hasil klasifikasi didapatkan kelas penggunaan lahan dimana kelas tersebut dilakukan kajian terhadap RDTRK. Kelas yang paling dominan kesesuaian dari sampel adalah pemukiman 478,830 ha, industri 40,0173 ha, tambak 572,205 ha, sedangkan luasan kelas lainya tidak sesuai yaitu 160,616 ha, lahan kosong 65,229 ha. Citra mampu menampilkan objek yang sesuai dengan RDTRK namun ada beberapa kelas yang dimasukan ke dalam kelas lain yaitu fasum dan perdajas, fasum dan perdajas memiliki karaketeristik piksel dan bentuk yang sama dengan kelas pemukiman sehingga dalam melakukan identifikasi menjadi rancu oleh karena itu kelas fasum perdajas dikelompokan ke dalam kelas pemukiman.

\section{PENUTUP}

\section{Kesimpulan}

Pada penelitian Tugas Akhir ini dapat disimpulkan bahwa :

a. Kajian citra resolusi tinggi menggunakan klasifikasi dijital dan interpretasi manual menghasilkan 7 kelas tutupan lahan yaitu : tambak, semak belukar, sungai, pemukiman, industri, jalan, dan lahan kosong dengan ketelitian dari klasifikasi sebesar $89,7 \%$

b. Luas pemukiman 478,830 ha, industri 40,0173 ha, semak belukar 160,616 ha ha, lahan kosong 65,229 ha.

\section{Saran}

Adapun saran yang diberikan dari penelitian Tugas Akhir ini adalah sebagai berikut ;

1. Perlu dilakukan penelitian lebih lanjut mengenai pengolahan citra resolusi tinggi sebagai data dasar RDTRK dengan menggunakan metode klasifikasi dijital dan manual untuk mendapatkan hasil klasifikasi yang lebih baik.

2. Perlu dilakukan penelitian lebih lanjut mengenai penggunaan metode klasifikasi terbimbing dalam melakukan pengolahan citra, agar hasilnya lebih baik.

3. Perlu dijadikan masukan ataupun rekomendasi terhadap Pemerintah Kota Surabaya untuk penyusunan RDTRK sesuai dengan kebijakan tata ruang yang ada.

\section{DAFTAR PUSTAKA}

Andreson, James R., Hardy, Ernest E., Roach, John T., andWitmer, Richard E. 1976. A Land Use and Land Cover

Classification System for Use with Remote Sensor Data. Washington : United States Government Printing Office.

Anderson, J. R. 1971. "Land Use Classification Schemes Used in Selected Recent Geographic Applications of Remote Sensing". Photogramm.Eng. 37, 4: 379-387.

Danoedoro, Projo. 1996. Pengantar Penginderaan Jauh Digital. Fakultas Geografi Universitas Gajah Mada. Yogyakarta.

Danoedoro, P. 2012. Pengantar Penginderaan Jauh Digital.Yogyakarta : Andi.

Lillesand, T. M., Kiefer, \& Chipman, J. 2008. Remote Sensing and Image Interpretation 6th Edition. New York: John Wiley and Sons. 
Richards, J. A., \& Jia, X. 2006. Remote Sensing Digital Image Analysis an Introduction, Fourth Edition. Berlin: Springer-Verlag.

\section{Lampiran}

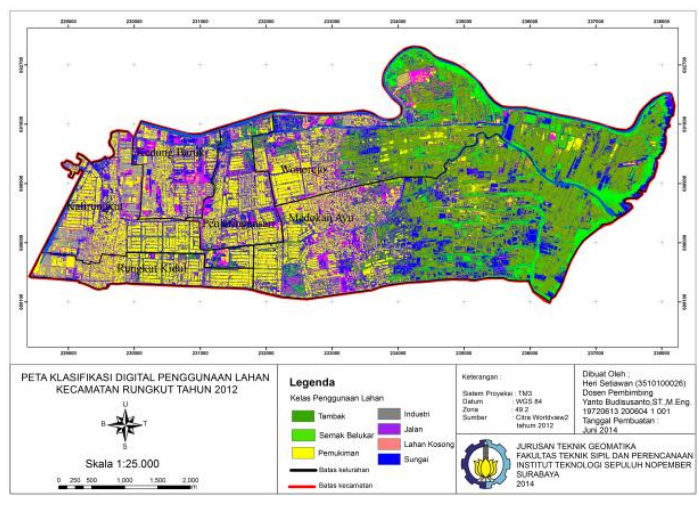

